\title{
A IMPORTÂNCIA DO DESIGN EDUCACIONAL NA CRIAÇÃO DE UM AMBIENTE VIRTUAL DE APRENDIZAGEM
}

Paulete Fridman Schwetz-paulete.schwetz@ufrgs.br Universidade Federal do Rio Grande do Sul (UFRGS) Av. Osvaldo Aranha, 99 - sala 408

CEP 90035-190 - Porto Alegre - RS

Jocelise J. Jacques - jocelise.jacques@ufrgs.br Universidade Federal do Rio Grande do Sul (UFRGS)

Av. Osvaldo Aranha, 99 - sala 408

CEP 90035-190 - Porto Alegre - RS

Anelise T. Hoffmann - anelise.hoffmann@ufrgs.br

Universidade Federal do Rio Grande do Sul (UFRGS)

Av. Osvaldo Aranha, 99 - sala 408

CEP 90035-190 - Porto Alegre - RS

Dinara Dal Pai-dinadesign21@gmail.com

Universidade do Vale do Rio dos Sinos (UNISINOS)

Av. Unisinos, 950

CEP 93022-750 - São Leopoldo - RS

Resumo: Este artigo discute a importância do design educacional centrado no usuário na criação de ambientes virtuais de aprendizagem. A partir de uma reflexão sobre ensino a distância e design visual empático de ambientes virtuais, descreve-se uma atividade prática de desenvolvimento de um Ambiente Virtual de Aprendizagem (AVA) para uma disciplina fictícia de Design de Superfície, ofertada na modalidade a distância para estudantes de graduação.

Palavras-chave: Design Educacional, Educação a distância, Ambiente Virtual de Aprendizagem

\section{INTRODUÇÃO}

O desenvolvimento dos recursos tecnológicos, nas últimas décadas, motivou progressivos investimentos na Educação a Distância $(\mathrm{EaD})$, tornando-a promessa para a ampliação do acesso à educação e transformação necessária na experiência de aprendizagem em salas de aula presencial e virtual (TAPSCOTT, 1999; OLIVEIRA NETTO, 2005; LÉVY, 1999). Na $\mathrm{EaD}$, docentes e discentes não compartilham de um mesmo espaço físico e muitas vezes não interagem de modo síncrono, fazendo-se necessária a utilização de um Ambiente Virtual de Aprendizagem (AVA) para mediar os processos de ensino e aprendizagem (BEHAR, 2009, p. 1-16).

Em março de 2020, a necessidade de distanciamento social como medida de contenção ao avanço do Covid-19 no território brasileiro inaugurou um movimento de rápida migração das atividades de sala de aula presencial, no ensino superior, para a modalidade do Ensino 
Remoto Emergencial (ERE), com o apoio de AVAs. Nesse contexto, muitos professores, habituados com a modalidade presencial, foram desafiados a repensar os seus planos de aula para interações a distância. Com isso, tiveram de se familiarizar com muitos conceitos e ferramentas usados no EaD.

O AVA, frequentemente utilizado como repositório de conteúdos na modalidade presencial, passou a ter um novo significado nas rotinas desses alunos e professores, que tiveram que entender o uso da interface e dos recursos disponíveis em um curto espaço de tempo. Para Hodges et al. (2020), esses movimentos apressados podem causar a falsa impressão de que a aprendizagem online é uma opção de qualidade inferior, quando, na verdade, não foi feita uma transição adequada para tirar o máximo proveito dos recursos e possibilidades do formato online. É preciso preparar os professores para uma nova realidade de ensino até então desconhecida, auxiliando-os no desenvolvimento de novas habilidades, no planejamento das aulas em AVA e na criação de estratégias de ensino e avaliação, em um cenário em que as interfaces e a comunicação visual ganham relevância.

O design visual de AVA é um tema pouco explorado pelas áreas de design e educação. Contudo, as intensas demandas no uso desse ambiente têm chamado a atenção sobre a importância de uma interface acolhedora, organizada e agradável para professores e alunos. Segundo Torrezzan e Behar (2009), a usabilidade do AVA é um fator importante, pois quanto mais facilmente o usuário descobrir o funcionamento e a relação de links, maior liberdade e confiança ele terá nas suas ações. Nesse sentido, habilidades de planejamento e comunicação visual tornam-se importantes para a plena atuação docente em um contexto de interações virtuais mediadas por interfaces e tecnologias que exigem a seleção de tipografias, cores e imagens como formas de comunicação. Assim, ainda que exista um padrão específico estabelecido pela instituição para o seu AVA, existem possibilidades de edição para o professor que podem apoiar ou prejudicar a experiência de aprendizagem do aluno.

Este artigo objetiva descrever possibilidades de aperfeiçoamento do AVA, tendo como exemplo o desenvolvimento de um AVA Moodle para uma disciplina fictícia de Design de Superfície no ensino de graduação. Nesta construção, realizada em 2019 no contexto da disciplina de Design Educacional Aplicado ao E-learning do Programa de Pós-Graduação em Design da Universidade Federal do Rio Grande do Sul, considerou-se os desafios do design visual empático em ambientes virtuais.

\section{EMPATIA E DESIGN VISUAL}

Nas interações humanas, como é o caso das experiências de ensino-aprendizagem, destaca-se a empatia. Segundo Brown (2017, p. 47), a empatia é a tentativa de enxergar o mundo através dos olhos dos outros, de compreender o mundo por meio de experiências alheias e de sentir o mundo por suas emoções. De acordo com Matthews et al. (2017), a empatia também é fundamental na prática projetual da EaD, surgindo pela preocupação e cuidado dos designers educacionais com a experiência de aprendizagem proposta para o aluno, pelas memórias de quando eram estudantes e pelo exercício de imaginação que os coloca no papel do discente. No processo de estruturação do AVA orientado pela empatia, surgem demandas pela criação de uma interface organizada e de fácil navegação, capaz de estabelecer uma comunicação clara e agradável, não apenas por meio de textos, mas sobretudo por imagens.

Assim, a adequada expressão visual impõe-se aos designers educacionais como uma necessidade no desenvolvimento de AVAs. Dondis (2015) ressalta a importância do que ele chama de alfabetismo visual, um processo que apresenta um sistema visual complexo, mas 
que pode ser articulado com vistas à criação de significados. Para o autor, a complexidade inerente à sintaxe visual não se opõe a ideia de definição quando os seus elementos básicos - a saber: ponto, linha, forma, direção, tom, cor, textura, dimensão, escala e movimento - são articulados de forma eficiente para a comunicação de uma determinada mensagem. Neste artigo, tem-se foco na exploração dos significados relacionados ao uso de três elementos importantes para a configuração visual de um AVA: forma, cor e escala.

As três formas básicas, quadrado, triângulo equilátero e círculo, são figuras planas originadas pela linha. Cada uma delas, possui características específicas que despertam diferentes significados. $\mathrm{O}$ quadrado pode estar associado à honestidade, à retidão e ao esmero; o círculo à infinitude, à proteção; já o triângulo é relacionado à ação, ao conflito e à tensão (DONDIS; 2015). Os tipos, isto é, o conjunto de letras, números, símbolos e pontuação com um determinado estilo visual utilizados nos processos de comunicação sugerem uma forma. Sendo assim, "a tipografia é o meio pelo qual é dada uma forma visual para uma ideia escrita"(AMBROSE; HARRIS, 2011). Sobre forma e tipografia, destacam-se os diferentes estilos e anatomias que refletem questões históricas, contextuais e tecnológicas. Segundo Ambrose e Harris (2011), é possível dividir os tipos em quatro categorias básicas, cada uma, com diferentes funcionalidades e significados: (i) gótica (estilo ornamentado predominante na Idade Média), (ii) romana (tipo com acabamento de serifa presente nas inscrições romanas e que possui excelente legibilidade), (iii) grotesca (design limpo e sem serifa) e (iv) escritural (imitam a letra feita a mão e são recomendadas para textos curtos).

Relacionar tamanho, forma e significado é essencial na estruturação da mensagem visual. Assim, a escala surge da relação de um elemento com o outro e pela interpretação que pode ser alterada à medida que são inseridos novos elementos e pistas visuais (DONDIS, 2015, p. 72).

Em relação aos elementos básicos de comunicação visual, a cor assume papel de destaque ao estabelecer maior afinidade com as emoções, ser associada ao meio ambiente e ser interpretada a partir de questões simbólicas e subjetivas (DONDIS, 2015). Segundo Heller (2013), a cor pode produzir efeitos contraditórios e despertar sentimentos diferentes. Nesse sentido, "o mesmo verde pode atuar de modo salutar ou venoso, ou ainda calmante. O amarelo pode ter um efeito caloroso ou irritante" (p. 17). Para a autora, essa interpretação vai depender do contexto e das combinações com outras cores.

Tendo em vista essas questões básicas de comunicação visual, na próxima seção é descrito o processo de criação do AVA objeto deste estudo.

\section{O PROCESSO DE CONSTRUÇÃO DO AVA}

Na construção do AVA, em um primeiro momento, conforme já citado, é fundamental a reflexão sobre o perfil do aluno na configuração da arquitetura pedagógica, uma vez que são grandes os desafios para o engajamento e para a redução da evasão de estudantes._Por isto, no princípio do desenvolvimento do AVA para o curso fictício de Design de Superfície, a primeira questão que se impôs - Para quem fazemos o curso? - indicou a necessidade de compreensão do perfil do aluno.

O curso seria destinado aos estudantes de Design da Universidade Federal do Rio Grande do Sul e, por esse motivos, iniciou-se um processo de reflexão com a finalidade de buscar as memórias das autoras quando estudantes, procurando estabelecer um paralelo com as características dos alunos hoje presentes em sala de aula, uma vez que as autoras também são docentes. Para tornar visível e sintetizar aspectos importantes relacionados ao grupo de alunos, optou-se pela criação de uma persona, entendida como uma técnica de 
(C) COBENGE 2020

"Os desafios para formar hoje o engenheiro do amanhã"

desenvolvimento de personagens fictícios através de dados relacionados aos usuários, com o objetivo de representar suas características e necessidades (Figura 1). A persona traz informações textuais e visuais importantes sobre os potenciais alunos do curso, evidenciando características importantes para a configuração do AVA. Chama atenção o fato da Brenda, nome escolhido para a persona, ser superconectada, elemento este que sugere o hábito de navegar na internet por meio do uso do celular, utilizando softwar e aplicativos com interfaces atrativas, como Facebook e Instagram. Por outro lado, a sua impaciência a leva a desistir daquilo que incomoda ou demora muito para funcionar. Diante da análise dessas e de outras características, considerou-se fundamental trabalhar um interface atrativa e de fácil uso.

Figura 1 - Persona Brenda

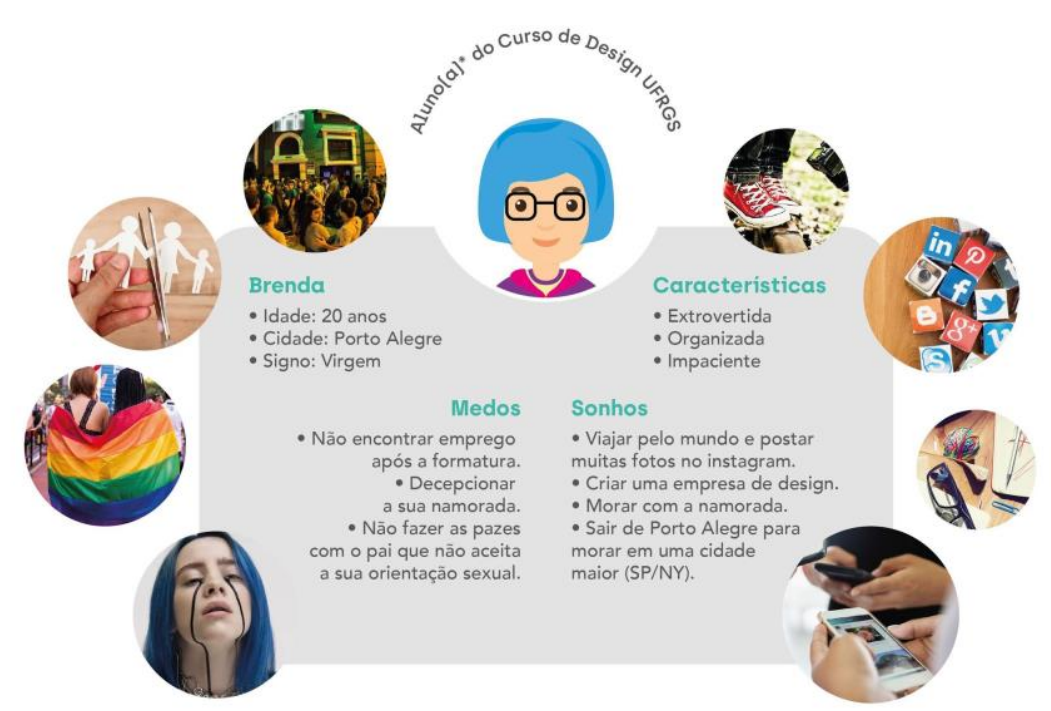

Fonte: desenvolvido pelas autoras.

Quando o AVA é o principal meio de interação entre professor e aluno, torna-se fundamental planejar esse espaço de forma que a comunicação seja clara, direta e atrativa. Nesse sentido, aspectos de comunicação visual ganham relevância, uma vez que cores, formas e tipografias podem auxiliar na organização dos conteúdos e tornar visível a lógica sequencial da experiência de aprendizagem proposta. Para tanto, criou-se um sistema de identidade visual que pode ser observado na Figura 2. 
Figura 2 - Sistema de identidade visual para o Curso Design de Superfície

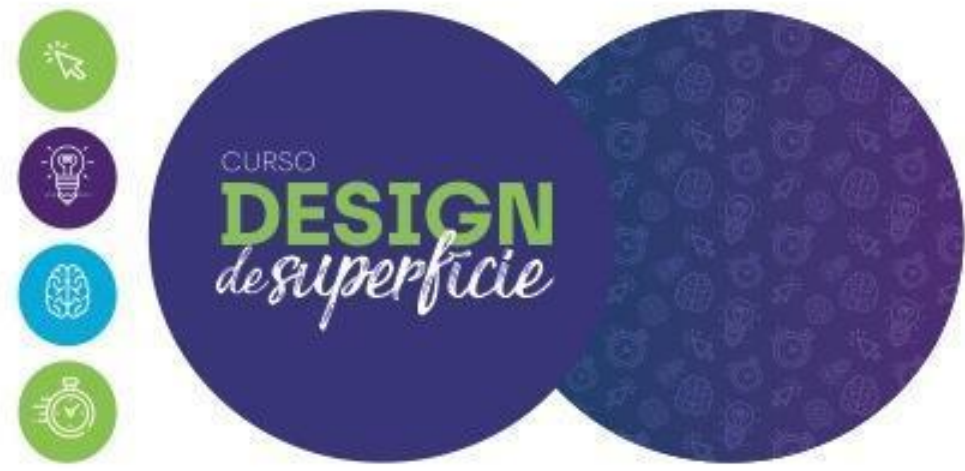

Fonte: desenvolvido pelas autoras.

O sistema de identidade visual possui uma assinatura visual composta por duas tipografias. A combinação desses estilos, um com traços marcantes e retos (com e sem serifa) e a outro com traços orgânicos e leves (escritural), comunica visualmente irreverência e transmite a ideia de interação humana. As cores selecionadas foram o verde, o roxo e o azul, cores essas que apresentam um bom contraste e uma vibração que dialoga com o perfil do jovem. Além disso, foram selecionados alguns ícones para a criação de uma estampa e para a sinalização dos recursos presentes no curso.

O curso foi estruturado em dois módulos assíncronos com período de duração de dois meses (um mês por módulo), seguindo a sequência apresentada na Figura 3. Ressalta-se, o uso de recursos distintos (videoaula, texto e atividade prática) para a exploração dos conhecimentos, buscando contemplar várias formas de aprendizado. Além disso, o modelo propõe um processo de autoavaliação que sugere avançar no módulo ou reforçar os estudos.

Figura 3 - Modelo pedagógico Ead

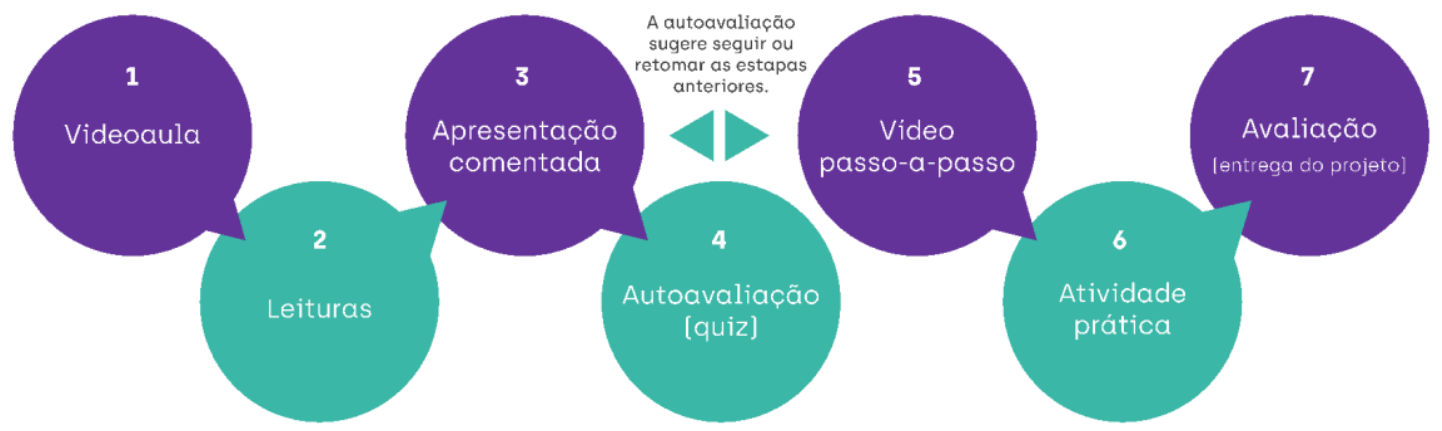

Fonte: desenvolvido pelas autoras.

A parte prática do curso considera a apresentação de uma demanda para um projeto criativo e de um vídeo passo-a-passo que explica a técnica necessária para avançar no projeto. Ressalta-se que todos os vídeos utilizam o recurso embutir para que fiquem visíveis e tenham acesso rápido pela interface do AVA. Para comunicar as propostas do modelo e promover a experiência de aprendizagem desejada, Cabral e Cavalcante (2010) destacam a importância do uso de uma linguagem verbal escrita adequada, que servirá tanto para a transmissão de conteúdos, quanto para a interação entre professor e alunos e dos alunos entre si. Os autores recomendam, ainda, o uso de uma linguagem simples e clara, a fim de minimizar os 


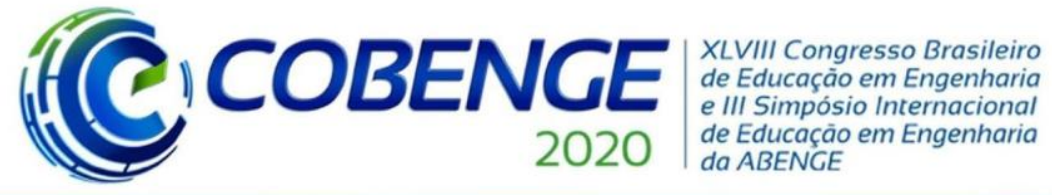

"Os desafios para formar hoje o engenheiro do amanhã"

desencontros de compreensão, pois haverá uma assincronia na interação intermediada pelo computador, sendo assim uma estratégia eficaz para a aproximação e engajamento do aluno.

No AVA, a sequência de atividades pode ser organizada por módulos, períodos de tempo ou por aulas, conforme a estratégia definida pelo professor. Os conteúdos e recursos também podem ser disponibilizados desde o início do curso ou "liberados" no decorrer do curso, em datas específicas (isto pode ser realizado de forma automática, através da programação simples dos recursos AVA). Destaca-se aqui que, no curso criado, optou-se pela liberação gradual dos conteúdos e recursos, pois essa prática diminui a ansiedade. Além disso, a liberação do segundo tópico foi condicionada à entrega do primeiro projeto, buscando assegurar que o aluno realize as atividades previstas pelo primeiro módulo antes de iniciar o segundo. Segundo Behar (2009), a proposta pedagógica deve ser apresentada no início do curso, especificando as expectativas em relação ao rendimento, os pré-requisitos ou condições tecnológicas em que ocorrerá o curso ou disciplina. Para tanto, é recomendada a utilização de um tópico de introdução com uma breve apresentação visual e textual da disciplina, conforme mostra a Figura 4.

$\mathrm{Na}$ proposta desenvolvida (https://youtu.be/asgJNX8QxKo), buscou-se organizar um ambiente acolhedor e informal por meio da criação de uma imagem de apresentação do curso com assinatura visual e a frase seja bem-vindxs. O uso da letra " $x$ " no lugar da letra "o" traz um exercício de empatia em relação à persona Brenda, que é crítica em relação à identidade de gênero. Além disso, as professoras foram apresentadas com imagens informais, similares àquelas utilizadas em redes sociais. A linha do tempo do curso destaca as datas e os períodos de avaliação, informações fundamentais para o aluno entender o seu compromisso em relação ao curso e poder se organizar. 
Figura 5 - Organização visual do módulo 1

O que é design de superficie

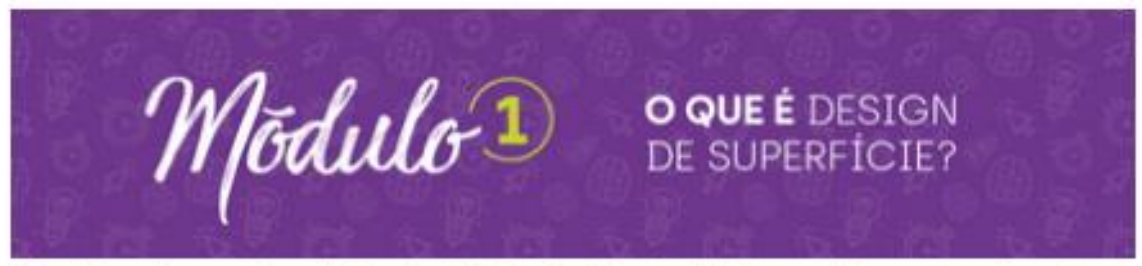

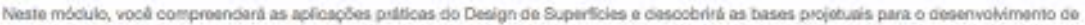

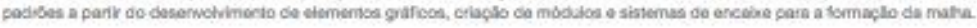

\section{VIDEO AULA}

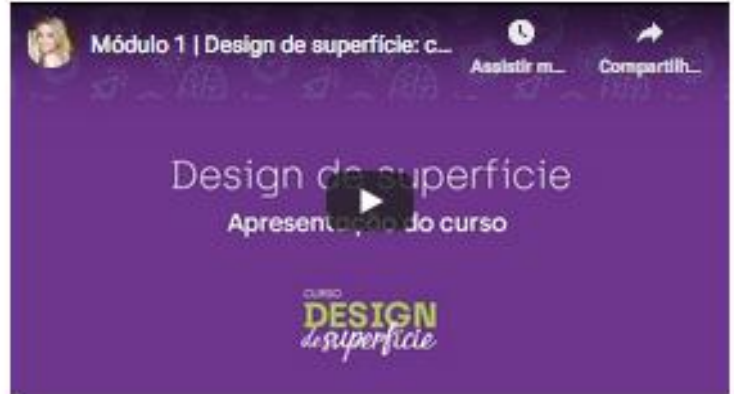

\section{LEITURAS}

() Design os Sucerficie para a cominicaplo Vsuad

\section{APRESENTAÇÄO COMENTADA}

(2) Design do Sugarticies a Mathas

\section{AUTOAVALIAÇÃO}

응 ouz

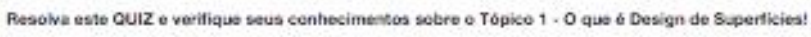

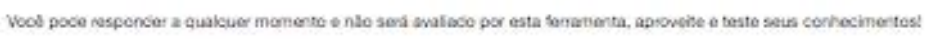

Fonte: desenvolvido pelas autoras.

As imagens possuem grande potencial na organização do AVA. Torrezzan e Behar (2009) ressaltam que seu uso dependerá do público-alvo e do assunto abordado, mas quando bem contextualizada pode encurtar o caminho à compreensão. Porém, é importante destacar que, quando usadas de forma meramente ilustrativa ou fora de contexto, podem confundir o usuário. Neste sentido, os signos utilizados devem estar compatíveis com o discente, para propiciar um equilíbrio entre o esforço mental e o efeito obtido. Segundo as autoras, quanto maior o efeito e menor o esforço, maior a relevância. Como consequência, muitas vezes uma imagem chama mais atenção que um texto, pois sua interpretação é mais rápida.

No que diz respeito aos recursos utilizados, chama-se atenção para o fórum. Essa ferramenta pode ser utilizada para discussões sobre determinado assunto entre os alunos e 
entre alunos e professor, promovendo o debate entre todos os membros do processo. Para Cabral e Cavalcante (2010), o fórum permite a socialização, a troca de experiências e saberes, proporcionando a aprendizagem coletiva através da presença constante de um mediador para direcionar e orientar os comentários, encaminhando aos objetivos do trabalho a ser desenvolvido. No curso criado, este recurso foi selecionado para que os alunos compartilhassem dúvidas e descobertas com todos os participantes do curso.

Uma outra questão importante em uma AVA diz respeito à possibilidade de autoavaliação por parte do aluno. Com o objetivo de proporcionar esta alternativa, selecionouse o recurso Quiz, o qual permite que o aluno leia a questão e assinale uma das alternativas de resposta. Caso a alternativa esteja incorreta, ele recebe, automaticamente, uma mensagem, explicando qual seria a resposta correta. O AVA permite a criação de um banco de questões, que podem ser sorteadas pelo sistema de forma aleatória e gerar feedbacks.

Para a entrega das avaliações, selecionou-se o recurso tarefa, uma vez que o modelo pedagógico estabelecia a entrega de projetos ao final de cada módulo. Na descrição da tarefa, foram expostas orientações claras sobre a avaliação, de forma a complementar o vídeo com a fala das professoras. Nesse espaço, sugeriu-se o envio dos arquivos em extensão pdf, para evitar problemas tecnológicos e permitir rápido acesso e visualização.

\section{CONSIDERAÇÕES FINAIS}

O ano de 2020 está sendo marcado pela rápida transformação do fazer docente, na medida em que ocorre a apropriação de um grande número de TICs para a manutenção das atividades no sistema de ERE. Nesse contexto, a tão desejada inovação das práticas de ensino e aprendizagem, a partir do uso das ferramentas tecnológicas disponíveis, mostra o seu valor na construção de uma experiência de sala de aula flexível em relação ao espaço, mas que proporciona alternativas de interação e construção de uma relação empática entre professores e alunos.

Assim, se por um lado o distanciamento social isolou discentes e docentes em suas casas, por outro, os uniu enquanto humanos que aprenderam juntos em um momento de extrema incerteza. Nesse cenário, o AVA ampliou a sua relevância e substituiu a sala de aula, passando a ser o espaço de acolhimento, que centraliza as informações mais importantes da disciplina e organiza a lógica das atividades. Diante disso, a percepção do aluno em relação à qualidade desse espaço, a clareza das informações e o desejo de permanecer conectado ao AVA, são aspectos importantes a serem considerados.

O material educacional produzido para qualquer uma das modalidades de ensino (EaD, ERE ou presencial) deve levar em consideração as características específicas de cada ambiente e, sobretudo, questões de empatia com o aluno a que se destina, para que sirva de apoio ao seu aprendizado. Na experiência descrita por este artigo, mostrou-se a pertinência do design educacional, a partir do design visual com linguagem complementar aos recursos de texto, vídeo e áudio, uma vez que ele auxilia a exploração da interface pelo aluno e organiza o curso ou disciplina. Além disso, a linguagem visual pode ser um potente recurso para despertar emoções positivas, estimular a frequência e demonstrar para o aluno o cuidado do professor em relação àquela experiência. Assim, diversificar as formas de comunicação parece um caminho importante a ser percorrido quando o assunto é prepararmos os professores para um futuro onde as interfaces tecnológicas serão cada vez mais usadas como mediadoras das experiências de aprendizagem.

\section{REFERÊNCIAS}




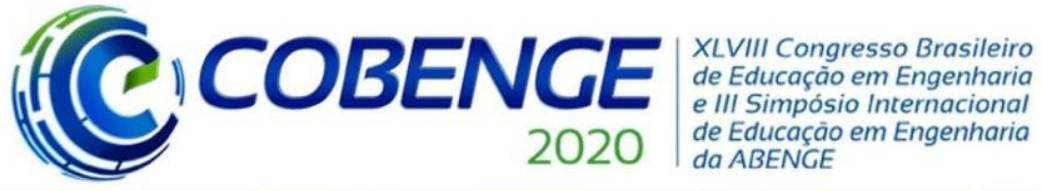

"Os desafios para formar hoje o engenheiro do amanhã"

AMBROSE, Gavi; HARRIS, Paul. Tipografia. Porto Alegre: Bookman, 2011.

BEHAR, Patricia Alejandra. Modelos pedagógicos em educação à distância. In.: BEHAR, P. A. e cols. Modelos pedagógicos em educação à distância. Porto Alegre: ARTMED, 2009.

BROWN, Tim. Design Thinking: uma metodologia poderosa para decretar o fim das velhas ideias. Rio de Janeiro: Alta Books, 2017.

CABRAL, Ana Lúcia Tinoco; CAVALCANTE, Alessandra Fabiana. Linguagem escrita. In: TARCIA, R. M. L.; CARLINI, A. L. 20\% à distância: e agora? : orientações práticas para o uso de tecnologia de educação à distância. São Paulo: Pearson Education do Brasil, 2010.

DONDIS, Donis A. Sintaxe da linguagem visual. 3 ed. São Paulo: Martins Fontes-selo Martins, 2015.

HELLER, Eva. A psicologia das cores: como as cores afetam a emoção e a razão. 1 ed. São Paulo: Gustavo Gili, 2013.

HODGES, C. et al. The Difference Betw0een Emergency Remote Teaching and Online Learning | EDUCAUSE, 2020. Disponível em: < https://er.educause.edu/articles/2020/3/thedifference-between-emergency-remote-teaching-and-online-learning >. Acesso em: jun. 2020

LÉVY, Pierre. Cibercultura. 3 ed. São Paulo: Editora 34, 1999.

MATTHEWS, Michael et al. Empathy in distance learning design practice. TechTrends, v. 61, n. 5, p. 486-493, 2017.

OLIVEIRA NETTO. Alvin Antônio de. Novas tecnologias e universidade: da didática tradicionalista à inteligência artificial. Petópolis: Vozes, 2005.

TAPSCOTT, Don. Geração Digital: a crescente e irreverssível ascensão da geração net. São Paulo: Makron Books, 1999.

TORREZZAN, Cristina A. W; BEHAR, Patricia Alejandra. Parâmetros para a construção de materiais educacionais digitais do ponto de vista do design pedagógico. In.: BEHAR, P. A. e cols. Modelos pedagógicos em educação à distância. Porto Alegre: ARTMED, 2009.

\section{THE IMPORTANCE OF EDUCATIONAL DESIGN IN THE DEVELOPMENT OF A VIRTUAL LEARNING ENVIRONMENT}

Abstract: The aim of this work is to discuss the importance of user-centered educational design when creating virtual learning environments (VLE). Based on a reflection on distance learning and empathetic visual design of virtual environments, a practical activity for the development of a VLE is described for a fictional discipline of Surface Design offered in distance learning course for students of graduation.

Keywords: Educational Design, Distance Learning, Virtual Learning Environments 